\title{
Jogo e performance artística
}

\author{
Maria Assunção Pestana \\ Investigadora e Artista Intermédia
}

\begin{abstract}
Resumo
O presente trabalho tem como objetivo principal valorizar a expressão integrada versus performance artística-jogo interactivo, no campo da arte e espaços socioeducativos.Neste contexto optamos pela metodologia qualitativa de tipo sócio-construtivista e narratológica, considerada adequada numa investigação deste teor, simultaneamente socioeducativo e artístico. Problematizamos ainda, esta prática como potenciadora no reactivar de novas práticas artísticas, descortinado estratégias e modos de actuação.Por último e, numa visão ampla

expandida socioeducativa,pluricultural/interdisciplinar,referimos a importância dos ambientesalternativos, agentes e espaços difusores, como promotores socioculturais desta prática artística e suamanipulação digital posterior dos seus registos vídeo gravados, sua singularidadeestética.

Palavras-chave:jogo,performance,expressõesintegradas, dinâmicas socioculturais.
\end{abstract}

\section{Modalidades e contextos do jogo performativo - imagens, jogo-espacial e jogo presente em serviços educativos}

O jogo na sua versão lúdica, educacional ou mesmo terapêutica, destaca-se na história humana como marcador cultural, desde as sociedades ancestrais àsmais contemporâneas.Este permite uma abordagem em consonância com o actual paradigma educacional e digital com repercussão socioeducativa, por perspetivar diferentesmanifestações interculturais regionais/globais e cultura artística.A importância desta abordagem não se limita apenas às questões artísticas e educativas,geradas pelo jogo e performance, mas advém do facto também ela poder contribui e incentivar para uma reflexão sobre práticas artísticas em diferentes espaçose intervenções públicas.

Veja-se o caso do desafio proporcionado porprojetos específicos artísticos, como site-specific-project-based, na versão de objetos móveis e recriados por artistas, onde a educação artística e serviços socioeducativospoderão contribuir para a sua divulgação,comsuas oficinas lúdicas e artísticas na sua promoção e divulgação (Regatão, 2007).Anote-se que, quando nos referimos àperformance artística significa enquadrá-la no espectro amplo das Artes Visuais.

Assim, equaciona-se neste exposição a importância do jogo expressivo/interactivo, no quadro das expressões artísticas integradas/performance artística, como vetor impulsionador de diferentes dinâmicas intersociais, grupo e/ou individual, neste caso particular, no quadro conceptual mais detalhado das formas artísticas/área Intermédia/Expressões Integradas/Arte Digital. Estas situam-se num âmbito da experiência individual e coletiva - intervenção/performance artística, porpermitir evocar imagens, documentais e ficcionadas, associadas a tradições, usos, comportamentos e espacialidades tecnológicas e respetivastécnicas artísticas, antigas e/ou contemporâneas,separadas ou em simultaneidade. Visa ainda, destacar a dimensão socioeducativa, simbólica, sígnica, implícita no acto de jogar expressivamente, com suas estratégias e processos de recriação e por tal, apresentandoconfigurações socioculturais próprios. Esta abordagem procuraainda focalizar os modos e processos recreativosàs diferentes práticas artísticas em espaços (in)formais;expressividades identitárias que se manifestam em diferentes contextos socioeducativos, a partir da prática do jogo expressivo integrado, interactivo, dirigido a públicos-alvoespecíficos.

Ora por acaso, ora normativo, sabemos que o jogo em sentido lato, constitui-se um artefacto cultural de interessante investigativo, já que permite abordar tipos de habilidades, físicas, mentais e afetivas desenvolvidas pelos indivíduo/grupo, em diferentes espaços,classes etárias esociais, ou ainda, registar dinâmicas discursivas contidas e expressas pelo corpo-material-espaço, denunciando culturas plurais de cariz identitário e transmissível (Ferrin,2002).

\section{Jogo e nichos sócio-artísticos}

Sabemos assim, que o jogo sempre se desenvolve em nichos próprios de grande complexidade social e educativa, quer em termos depráticas etécnicas, quer em função das suas especificidades e formatos.

Seja de caráter profano ou religioso, com papel elemento integrador e regulador, o jogo vincula uma caracterização complexa de diferentes conhecimentos, comportamentos e crenças, presentes nas comunidades e ainda, permite o (re)desenhar de estéticas e éticas patentes nos mesmos(Batllori, 2001).

Todavia, é nosso propósito demarcar um nicho exploratório temático, assente nas expressividades e produções artística, suportado num quadro conceptual da uma educação artística contemporânea e Ciências SociaisHumanas. Este procura destacar umparalelismo de recriação da prática artística, integrada, com base na prática do jogo expressivo e performance-artística (Argan,1988;Crispolti,2004).

Leva-nos também acentuar o jogo expressivo /interactivoe performance artística, como promotores de imagens-documentos, por relatarem experiências estéticas diferenciadas, pela capacidade de intercomunicação intrínseca expressiva,(re)formulação narratológica de formas aculturadas, ou mesmo, pelas ações pontuais de teor mais ou menos objetivo-subjetivo,remetendo-nos para anteriores enxertos dadaístas, happenings, ações intermédias, arte pública (Forkema,s/d). Enquanto produto social interventivo, esta performance artística - o jogo interactivo, expressivo, permite-nos trazer ao debate as 
diferentes dimensões sociais-lúdicas-criativas-afectivas relativas ao individuo, grupo e comunidade. Assim,aperformance como jogo - jogo expressivo/performance artística é entendida como um processo socioeducativo interdisciplinar, por estimular, questionar a realidade sociocultural de grupo e lugar onde esta se desenvolve, interpelar, interpretar imagens plasmadas expressivas de uma realidadesociocultural (Torres, 2008; Davis, 2008).

Junta-se a esta focalização sobre jogo expressivo corpo performativo, a perspetiva de expressões integradas, que embora alinheem diretrizes (pré) estabelecidas, se recria em gestos e objetos manipulados em diferentes protocolos e formatos de linguagens artísticas. Veja-se o exemplo do jogo da macaca que usa ao longo da sua prática, uma diversidade de materiais nos objetos de manipulação, que vão desde a sola de sapato, pedra à concha ou outros, dependendo do lugar e tempo onde o mesmo se prática e permitindo o um enquadramento sociocultural datado.A relação de contágio e entrosamento e sua desmaterialização, proposta pela moldura de arte conceptual adotada, permite desde modo, novas abordagens práticas do jogo expressivo, que se tornam explícitas,através da sua reapropriação e (re)apresentação, fixada em termosmultimédia.Como acção intermédia, integrada, este jogo expressivo-performance artística apresentada em espaços fechados ou abertos, geram diferentes reações às suas reinterpretações, aceitação ou conflito, com base nas artes visuais, expressão corporal, música e arte digital.Neste contexto, refira-se que a performance artística como acçãoartística integrada, multicultural , dada a sua capacidade de improvisação como dado inerente à sua concepção, cenários de acção plástica, visual, sonora, corporal,joga como se de um jogo expressivo se trata-se.

Salientamos ainda, a semelhança processual entre o acto de jogar e acto expressivo, tanto pela convergência de estratégias, renovação-reinterpretação de signos nos domínios, social e artístico, como nos domínios exploratório físico e digital, hoje. Com base, na potencial transmutação sígnica contida neste tipo de acção interventiva, fazem (sub)emergir novas constelações de signos meta-expressivos, que à sua vez, se manifestam e retroalimentam, sejam em forma de releituras de jogos tradicionais, sejam na configuração de outros tipos de performance artística contemporânea, refira-se a este propósito as obras performativas de artistas que sugerem esta dimensão estética, comoVostell, Paik, Kaprov, entre outros (Morel, 1979).

Deste modo, o jogo na sua feição lúdico-afetiva e cognitiva, assume-se como agente reactivo cultural de diferentes contextos vivenciais onde este se desenrola, Levam-nos pois, a sugerir uma analogia processual do seu activo e recreativo e seu uso, JOGO-PERFOMANCE ARTISTICA,pela capacidade de improvisação e aculturação, embora se baseie num guião prévio, intermitente de vivências do autorartor-performer, através de uma atitude estética vinculada ao social.
Momentosestes de improvisação e singularidade, dada pela dimensão integradae replicação física e digital, de suas formas e imagensfixadas.

Ressalve-se que esta particularidade de improvisar, no acto performativo e patente no jogo expressivo, é desenvolvidapelo próprio artista intermédia que a concebe não decorrente da orientação de um realizador ou encenador exterior.

O jogo como forma identitária de um individuo, de umgrupo e de um espaço.Embora, se considere esta abordagem complexa em termos interpretativos, assentamos porém, que a mesma nos permite tratar um conceito de jogo amplo, indutivo, não unívoco seja como:

i. o jogo na sua vertente tradicional -clássica - jogo tradicional e actual.

ii. o jogo e sua vertente performativa assumida como artística - forma de expressão integrada.

iii. o jogo como espelho de diferentes tipos de estruturas socioculturais (in)tangíveis, inclusivo de modelos reprodutivos e suas práticas sociais serviço educativo.

Experienciamos estas práticas de jogo performativo, integrado, individual e em grupo (GICAP, Círculo de Artes Plásticas de Coimbra, 1978) tendo como orientador o escultor e professor Alberto Carneiro. Apresentou-se em diferentes apresentações públicas, abarcando temáticas e recursos reflexos de uma época particular vivida, em diferentes espaços e públicos e privados portugueses(anos 70/80. Denominado este grupo de artistas por grupo de intervençãoartística, este foi iniciático deste tipo de intervenção artística no panorama artístico português e influenciou posteriormenteo percurso de cada componente como artista e/ou docente, reutilizando este método e práticas nas suas práxis (Pestana, 2011).

Haverá ainda que,referir neste contexto e dada a especificidade temática desta pesquisa,o facto de termos optado por uma metodologia de tipo qualitativo, sócio-construtivista e narratológica,por considerarmos a maisadequada no tratamento artístico e educativo, flexível e largo espectro investigativo teórico-prático (Joannert, 2012; Bisqueira, 1989).

Deste modo, problematiza-seapotencialidade que esta performanceartística versusjogointeractivoapresenta como (re)activador de conhecimento artístico performativo integrado, com sua componente destacada de improvisação.

Assim, identificamo-nos como autores,Corrêa(2005) e Pestana, Mendes,Amaral(2012), quando estes destacam a relevância pedagógica e didática das expressões integradas na educação básica, por permitirem desde muito cedo, que as crianças possam experienciar e manusear signos de tipo corporal, espacial, sonoro integrado variado.

Neste contexto, defendemos o sistematizar e avaliar destas ações-jogos performativo-artístico em função do público-alvo e âmbitos socioeducativos mais alargados, com sejam, em associações/fundações/galerias e outros, fazendo propostas aos seus serviçoseducativos na região 
do Norte (exemplo da Casa de Imagem, Vila Nova de Gaia e Fundação José Rodrigues,Porto entre outras).

Por outro lado, ao situarmos estas ações transculturais nestes espaços, estamos a destacar as suas potencialidades difusoras artísticas e educativas inclusivas,que permitem projetarprojetos alternativos socioeducativos e inclusivos,hoje nesta região.

Acrescente-se que,esta vertente intermédia da performance artística-jogo faz intercomunicar as diferentes linguagens artísticas, por interagirem ese integrarem num todo formal, repleto de signos de jogos actuais e tradicionais(Batllori,2001;Cabral,1990).

Refletir sobre estasimagens plasmadas, híbridas física e virtuais, potencia debates sobre simbologias, ritos e, itinerários que interagem e se autorregulam.

Constatamos que nos actuais contextos sócio-artísticos o discurso da ficção-quotidiano constitui matéria da actual performance artística. Com seu amplo campo de exploração temático repleto de relatos de fragmentos de histórias de vida, este configura encenações intertextuais, interjeições e outras meta-narrativas, de feição mais lúdica e/ou artística ou, mesmo de pendor mais cognitivo, como os jogos de percepção, identificação ede comunicação não-verbal (Davis,1987).

Neste âmbito, faz-se ainda referência à actualampliação e mutação expressiva dada hoje pelo campo virtual, por avatares, ou ainda pela dimensão biótica, a extensão deexpressão e comunicação, apanágio da actualciência, dedicada à replicação de gestualidade, corporalidade e espacialidade, tornando-as as mesmas potencialmente significativas e extensivas (Arantes,2005).

Assim, o processo do acto de jogar/expressar integrado, artístico e vivencial, assume-se uma estrutura dinâmica num processo dialogante e continuado, corpo-espaço-público, quer pela reapropriação de formas, imagens e práticas traduzidas em tema e objeto cultural, quer pela interacçãodo performer, espaço e público-alvo.

Daí, considerarmos esta performance artística-jogointeractivocomo uma proposta intercultural para comunidades eserviços educativos, já que a mesma possibilita entrecruzamentos de várias áreas de conhecimentos, envolvendo domínios científicos diferenciados, numa concepção multidisciplinar investigativa.

Tal como, a performance artística, refira-se que o jogointeractivo projeta um discurso referencial próprio de teor afetivo, lúdico e cognitivo, que lhe é inerente por concepção. Do mesmo modo, as meta-narrativasconcebidas por manipulação, deformaçãotextual ampliam a capacidade criativa e imagética de temáticas versáteis.

As (sub)culturastangíveis no tecido social multicultural, por seu lado, ganham grande visibilidade nestas ações performativas, denunciando e vinculando identidades (e)imigratórias e seusquotidianos, individuais, grupais e comunitárias.

Adiantamos, por último, que estes artefactos efémeros, físicos/manipuláveis, resultantes desta prática artística, poderão constar numa listagem de material didático na ocupação dos tempos livres, programas de serviços educativos, já que os mesmos incentivam e orientam para prática artística, de grupo,integradora e integrada.

\section{Performanceartística-jogo interactivo - uma proposta pedagógica e didáctica}

Ao focalizarmo-nosna performance artística como jogo interactivo e suas práticas estéticas, importa uma vez mais destacar, a importância dosseusrecursos logísticose(re)interpretação e (re)produção, com base nas variações cenográficas e sonoplásticaspelas propostas formativas e lúdicas, numa linha exploratória que se pretende flexível e transmissível em termos socioculturais.

Assim, este tipo de performance adota significados múltiplos quando realizados em espaços diferenciados, veja-se o exemplo.de um objeto artístico exposto no espaço público -arte pública, eem galerias, museus, teatros ou escolas.

Neste sentido, evocamos também os museus,públicos e privados em especial de arte contemporânea, como espaços de interesse na produção e gestão destes projetosartísticos,com vista a uma programação mas actualizada dosseus serviços educativos(Aznar, \& Batista,2000).

Ao fomentar e aprofundar estas dimensões experimental e emocional implícita nesta prática estética, aperformance artística-jogo interactivopermite envolver diferentes tipos de público, formal/não formal, associada a processos reativos, estéticas e inclusivos. Ou seja, por valorizaro sentido crítico, estético e ético abre-se à cultura visual, sonora e cinestésica traduzindo-se $n$ aquisição de novas competências no âmbito cultural e social, em grupo ou individual,(Freedman, 2006).

Do mesmo modo, sendo a interdisciplinaridadesócio-artística,umaacçãointeractiva de conhecimentos cultural e artísticos que fomenta novas práticas estéticas integradas, ao dialogarcom determinadosartefactoslocais e comunitários, a mesma,faz emergir novas corporalidades, sonoridades, visualidades e arquiteturas. Remete-nos para uma dimensão estética multicultural.através dos seus contextos formativos, com simbologias que se interligam e se conjugam, num todo comunicativo social, singular e identitário.

Logo, a súmula destas aprendizagens artísticas que são decorrentes da prática da performance artística-jogo interativo-artístico, denota um enfoque híbrido ,transversal temático de áreas de conhecimento, privilegiando a História, a Estética, a Comunicação e Crítica, a Intermédia, entre outras.

Por outro lado,aestratégia metodológica, narratológica, faz do pesquisador um coletor e reflexivo sobre a grande diversidade simbólica, interdisciplinar e multissensorial em causa, basilar na educação estética e praxis educativa, hoje.

Estandoconscientes de que o ensino artístico actual se rege por uma redução significativacurricular detempos dedicados à educação artística, reclamamos mais propostas de práticas artísticas alternativas, como esta é disso exemplo nos espaços formais e não formais. Do mesmo modo, poderemos adiantar que a performance 
artística é também um terreno fértil de aquisição de habilidades específicas a desenvolver no ensino e aprendizagem, de acordo com o artista Robert Filliou (1970, citado por Torres,2007).

Dada esta dimensão pedagógica implícita nesta prática artística,resta-nos destacar a capacidade dos espaços difusores de cultura artística, de serem lugares privilegiados às práticas performativas, diferenciadas, nas comunidades onde estes estão inseridos.

\section{Roteiros e Espaços de aprendizagens e participação artística integrada}

Iremos definir, em seguida, cinco modos de actuacçãodirecionados aaprendizagens artísticas integradas, performance artística-jogo interactivo (baseado em propostas anteriores de dois autores Agra, 2001eBerrocal, 2005).

Como Menu listamos uma acção performativa integrada-jogo interactivotendo como ponto de partida o quadro conceptual interdisciplinar e transcultural.Segue-se a discussão individual ou grupo sobre a temáticaaeleger com base em propostas escritas anteriormente e apresentadas ao grupo. Junta-se à monitorização derecursos humanos e logísticos, os registos de ferramentas etempo de duração de acção.

Conclui-se este processo interventivo com a apresentação final da performance, individual ou grupo em espaços e seus públicos-alvo pré-definidos e sua (re)avaliação.Seguidamente,iremos sintetizar um guião que contempla vários passos de atuacção:

- Conceito (quadro e mapa conceitual);

- Procedimentos (eleição da temática, individual/grupo);

- Materiais e Suportes (relativos à meios de produção, cenografia e sonoplastia);

- Ferramentas (multimédia e materiais vários),Tempo (duração da planificação e acção);

- Processo de desenvolvimento de actividade(público alvo, registo da sinopse da actividade);

- Observações (a completar ao longo do processo criativo);

- Variações e Possibilidades (debate sobre novas propostas;

- Códigos a utilizarno design da actividade (para simplificação dos registos).

Assim, ao incorporarmos estas linhas de orientação comseus activadores criativos num guiãoaberto, reforçamos a presença de improvisações inerentes aeste tipo de jogo interactivo,como sua característica dominante (Prado,1998).Nestesentido,subjaz neste processo criativo momentos de observação,diálogo,reflexão, experimentação, recriação e avaliação da ação, contidos noscinco modos deste percurso:acção- participação-acção-reflexão-reacção, que passamos a citar:

- Modos de fazer: desenvolver um design e itinerário de conceitos, práticas e formação artística integrada, inserido ou não, num blogue de turma ou grupo, no caso da educação (in)formal,com registos de relatos de vivências, enquanto participantesactivos na acção.
-Modos de actuar: desenvolver um menuqueincluíaum mapa conceptual projectivo do processo de autoconstrução de conhecimento artístico, através da acção estratégica da recriação do jogo, como meta-narrativa performativa e artística.

-Modos de interagir: desenvolver a acção intercomunicativa artística de grupo/individual numprocesso dialógico e participativo.

-Modos de intervir: promover um espaço intercomunicativo,abertoao intuitivo e cognitivo, através da manipulação de linguagens artísticas integradas.

-Modos de reflexão crítica: dotar o aluno/observador/ participantede espírito crítico e reflexivo através da observação, participação e crítica de propostas artísticas estimuladoras da experiência estética, multissensorial, com base na realidade observada e ficcionada, posteriormente analisada e valorizada.

Assim, estes trabalhos resultantes da fusão de linguagens artísticas integradas, com tecnologias e técnicas bem definidas, permitem, desde logo, motivar para a diferença e inclusão artística e cultural, promover outras oficinas dimensionadas para a prática da intervenção artística, performanceartística-jogo interactivo.

Estes tipos de actividadespoderão assim,constar nos programas da animação dos tempos livres e ludotecas, através da produção de pequenas sinopses orientadas para determinados públicos, numa perspetiva da arte e educação artística contemporânea, conceptual da performance-arte e instalação-efémera.

Do mesmo modo, estes espaços socioeducativos não formais, incentivam a recriação de actosperformativos alternativospor grupos etários variados.

Ao defendermos este formato artístico-performance artística-jogo interactivocomo uma possível estratégia pedagógica e didática na actual educação artística integrada, propomos uma oferta diversificada formativa artística mais ampla, como vista a responder à falta de estratégiaseducativas, no campo da divulgação da artecontemporânea.

Ao proporcionarmos aos artistas e participantes a visibilidade das suas obras, através destas intervenções, estes tornam-se mediadores socioeducativos;abrem-se novas discussões sobre o papel da improvisação nainteracção-reacção artística, recriações e interações culturais.

Por último, acentuamos a importância de plasmar as formas resultantes desta intervenção artística, de caráterefémero por excelência, em registo videográficoe que por sua vez, se tornam peças de arte digital.

\section{Conclusão}

Com base num conceito abrangente de expressão integrada versus performance artística-jogo interactivo,partimos da configuração de um itinerário (re)criativo, que se distingue tanto pela capacidade de ruptura de padrões de ensino artístico-educativo e estética, como pelo confronto de ideias, ações e 
questionamentos, nareformulação de uma prática alternativa, performativaartística, lúdica e improvisadora, multidisciplinar e interactiva.

Assim, problematizamos o modo comoreactivar a prática artística em diferentes espaços socioeducativos, formais, informais e não formais, abertos e fechados, através da prática da performance artística-jogo interactivo, no quadro conceptual das expressões integradas e arte contemporânea. Desenhamos ainda, um menu orientador de estratégias, recursos e orientações flexíveis modos ecinco de acção-participação-acção-reflexão-reacção, no âmbito da prática desta performance artística.

Por último, salientamos a importância dos ambientes de (re)produção, gestão artística e educativana difusão e diversificação de oferta artística, como sejam museus, galerias fundações, escolas e espaços públicos, onde interdisciplinaridade a transculturalidadese constituem motores de novas percepções, práticas e reactivação de experiências estéticas.

Estamos conscientes pois, de que este modo de recriar e actuar artisticamente,abre-se a novas réplicas de práticas e investigações, nos âmbitosformativo e artístico.

\section{Referências}

Agra,M.J.(2001). Itinerarios de arte para la educaciónRevistaAula de Innovacióneducativa, (106)(22-26) Barcelona: Graó.

Arantes, P.(2005).Arte e intermédia.São Paulo:Senac.

Argan, G.C.(1988).Arte e Crítica de Arte. Lisboa: Editorial Estampa, Lda.

Aznar, F. F.\& Batista, M. V. (2000). El Juego de arte enlosMuseos. (301). EnBelver, M, H. \&Méndez M.S (coord.). Educación artística y arte infantil,.Madrid: Ediciones Fundamentos.

Berrocal, M. (coord.) (2005).Menús de educación visual y plástica. Barcelona: Graó.

Bisqueira,R. (1989).Métodos de investigación Educativa: Guíapirático. Barcelona: Editorial CEAC.

Batllori,J.(2001).Juegos de expresión artística. Barcelona: Parramón Ediciones.
Cabral, A.(1990).Teoria do Jogo. Lisboa: Editorial Noticias.

Corrêa,E.(2005). Expressões Integradas no Jardim-de-Infância - Projecto de Inovação e aprendizagem. Actas do $1^{\circ}$ CIANEI, ESE PF.Porto:Gaialivro.

Crispolti,E.(2004).Como Estudar a Arte Contemporânea. Lisboa: Editorial Estampa, Lda.

Joannert, P. (2012). Competências e socioconstrutivismo: um quadro teórico. Lisboa: Instituto Piaget.

Davis.F.(1987).LaComunicación no Verbal. Madrid:AlianzaEditorial.

Davis.C. (edit.). (2008).Performance Studies.Cambridge: Cambridge UniversityPress.

Pestana, A.(2011). Educação Artística, da prática artística à prática docente - as Pastas e os Blogues como dispositivos pedagógico-didácticos. Tese Doutoral, Santiago de Compostela:Faculdade de Educacíon: Universidade de Santiago de Compostela.

Pestana, A.,Mendes, A. \& Amaral,S. B. (2012). Projeto de Expressões Integradas. Atas do XII Congresso Internacional Galego-Portuguêsde Psicopedagogia. Braga: Universidade do Minho.

Prado, D.(1998).10 Activadores Criativos. Santiago de Compostela: Serviço de Publicações da Universidade de Santiago de Compostela.

Regatão, J.P. (2010).Arte Pública e os novos desafios das intervenções no espaço público. $2^{\circ}$ edição. Lisboa: Bicho-do-mato.

Freedman, K.(2006). Enseñarla Cultura Visual Curriculum, estética y la vida social da arte. Barcelona: Ediciones Octaedro.

Ferin, I.(2002) Comunicação e culturas do quotidiano. Lisboa: Quimera Editores.

Forkema, D.W.(s/d).Modernismo e Pós Modernismo.Lisboa: Veja.

Morel,J.I.(1979).HappeningdeHappenings.Barcelona: GranollersHappening.

Torres,V.(edit.). (2007). Pedagogía de la Performance. Programas de Cursos y Taller.Huesca: Diputación Provincial de Huesca. 